\title{
Research on the Improvement of Service Quality in Logistics Enterprises from the Perspective of Customer Satisfaction
}

\author{
Xiaoping Liu \\ Wuhan Technology and Business University, School of Management, Hubei, China \\ Liuxiaoping_0301@163.com
}

Keywords: Customer satisfaction, Service quality, Fuzzy comprehensive evaluation

\begin{abstract}
On the basis of the fuzzy comprehensive evaluation method, the paper establishes an index system for evaluating customer satisfaction for logistics enterprises according to investigation data. With Suzhou Yuan Cheng Logistics as the case, the paper analyzes problems logistics enterprises have in service quality under the perspective of customer satisfaction, puts forward specific improvement measures in aspects such as information management, target consumption group, service cost etc., which is of certain referential significance for logistics enterprises to improve their service quality of competitiveness.
\end{abstract}

\section{Introduction}

In order to meet the needs of the market, get better and longer term of development, more and more enterprises gradually realize the importance of customers. Enterprises begin to shift from product based competition to customer resource based competition. In essence, the management of logistics enterprises is to provide service for customers, provide products to logistics demand parties effectively and rapidly. The essence of modern logistics management is based on customer satisfaction. Nowadays, in order to obtain more customers, enhance customer loyalty and improve competitive advantage, more and more logistics enterprises focus on improving customer satisfaction and maintain good customer relationship. At present, although there are many academic researches pertaining logistics enterprise customer satisfaction, the research methods are different. From the perspective of customer satisfaction, this paper establishes the evaluation index system of customer satisfaction of logistics enterprises, using fuzzy comprehensive evaluation model to find out the main influencing factors of the satisfaction, and taking Suzhou Yuancheng Express as an example of empirical analysis.

\section{Construction of customer satisfaction evaluation index system for logistics enterprises}

In the early 1980 s, in order to obtain a favorable competitive advantage, AT\&T tried to understand customers' satisfaction of the services provided by enterprises and achieved certain results, which shall be served as a basis for improving service quality. On this basis, scholars have conducted in-depth studies from various countries and achieved remarkable results. Fenel's customer satisfaction index model (ACSI model) proposed in 1989 is more representative, which includes five aspects: customer expectations, perceived quality, perceived value, customer complaints and customer loyalty. The results are widely used to build national and industry customer satisfaction index systems. At present, the domestic research on the theory of customer satisfaction in logistics enterprises is in the ascendant. The research is focused on the quantitative research of customer satisfaction evaluation for regions, industries and enterprises.

$\mathrm{Wu} \mathrm{A} \mathrm{H}$ believes that the evaluation of customer satisfaction of logistics enterprises is influenced by many factors, and the relationship between various factors is difficult to achieve accurate quantification and complete certainty. The establishment of TPL's customer satisfaction evaluation index system by using the grey relation theory and AHP method includes five aspects: logistics enterprise image, logistics operation quality, logistics enterprises service level, cost and enterprise service persistence ${ }^{[1]}$. Musa A B put forward a new CSD evaluation method basing on the support of 
SVM, which set customer prior expectations as quantitative factor for the evaluation index, and the logistics activities in the CSD evaluation index system are summarized into two major indexes: the service quality and the product performance ${ }^{[2]}$. Huang B Q divided the composition of customer satisfaction index system of logistics enterprises into five parts, namely, the obtainable degree of satisfaction, the reliable degree of satisfaction, the quick response degree of satisfaction, the professional satisfaction degree of service personnel, and the comprehensive satisfaction degree of service $^{[3]}$. In order to overcome the limitations of the traditional method in determining the weight of each index of customer satisfaction evaluation, Zhang G Q adopts the concept of "entropy" in Information Engineering, adds two factors, namely brand effect of logistics enterprise, customer complaints $^{[4]}$. Hsiao H I uses the grey correlation analysis and grey clustering index screened the typical logistics enterprise customer satisfaction indexes, and through the evaluation index, he obtained seven representative indexes: punctual delivery, order cycle, deliver time, cost perception, customer behavior, technical services and goods packaging ${ }^{[5]}$.

At present, scholars at home and abroad have different research perspectives on the evaluation index system of customer satisfaction in logistics enterprises. This paper takes the customer satisfaction of logistics enterprises as the first level index, and establishes the evaluation index system of customer satisfaction of logistics enterprises from five aspects, namely, enterprise brand, service quality, service price, customer complaint and customer loyalty, which includes twenty level III indicators. On this basis, the comprehensive fuzzy evaluation is applied to evaluate the customer satisfaction of logistics enterprises, so that enterprises can recognize the existing problems of their own services, and offers convenience for the enterprise to understand the personalized needs of customers and helps to improve the core competitiveness of enterprises.

\section{Determine the weight of evaluation index}

After building the index system of customer satisfaction evaluation, we need to determine the weight of each factor. The weight of evaluation index reflects the importance of evaluation index relative to satisfaction. This study uses expert survey method to determine the weight of evaluation index of logistics enterprises' customer satisfaction. In the customer group which is close and long-term cooperated with logistics companies, we choose senior logistics managers with professional background and experience. Because these groups have a deep understanding of logistics service management, therefore we choose them as the respondents. A total of 30 experts from the industry were selected in the survey. The questionnaire on the weight of the customer satisfaction of the logistics enterprises was developed. 27 questionnaires were collected, and 3 questionnaires were disqualified by the consistency test. The effective questionnaires were 24 , with an effective rate of $80 \%$. The average value of the calculated number of the 24 questionnaires through the consistency test was obtained, and the weight of the final evaluation index was obtained, as shown in Table 1.

Table 1- weight of customer satisfaction evaluation index of logistics enterprises

\begin{tabular}{|c|c|c|c|c|}
\hline $\begin{array}{l}\text { Level I } \\
\text { Index }\end{array}$ & $\begin{array}{l}\text { Level II } \\
\text { Index }\end{array}$ & Weight & Level III Index & Weight \\
\hline \multirow{11}{*}{ 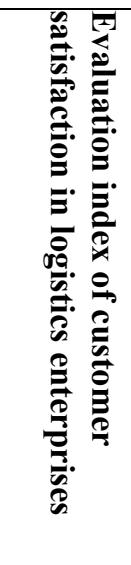 } & \multirow{4}{*}{$\begin{array}{l}\text { Enterprise } \\
\text { Brand }\end{array}$} & \multirow{4}{*}{0.19} & Brand Recognition & 0.20 \\
\hline & & & Enterprise Image & 0.15 \\
\hline & & & Equipment and Facility & 0.24 \\
\hline & & & Advancedness of Information System & 0.41 \\
\hline & \multirow{7}{*}{$\begin{array}{l}\text { Service } \\
\text { Quality }\end{array}$} & \multirow{7}{*}{0.41} & Employee Service Attitude & 0.06 \\
\hline & & & Punctual Delivery & 0.32 \\
\hline & & & Punctual Arrival & 0.32 \\
\hline & & & Tacking of Goods & 0.11 \\
\hline & & & Damage Rate & 0.13 \\
\hline & & & Timeliness in Handling Problem & 0.04 \\
\hline & & & Communication & 0.02 \\
\hline
\end{tabular}




\begin{tabular}{l|l|l|l|l}
\hline \multirow{2}{*}{$\begin{array}{l}\text { Service } \\
\text { Price }\end{array}$} & \multirow{2}{*}{0.2} & Price Acceptance & 0.46 \\
\cline { 3 - 4 } & & Cost Performance & 0.23 \\
\cline { 3 - 4 } $\begin{array}{l}\text { Customer } \\
\text { Complaint }\end{array}$ & \multirow{3}{*}{0.12} & Price Compare to Similar Enterprise & 0.31 \\
\hline \multirow{2}{*}{$\begin{array}{l}\text { Customer } \\
\text { Loyalty }\end{array}$} & \multirow{2}{*}{0.08} & Solving Time Satisfaction & 0.27 \\
\cline { 3 - 4 } & & Solving Process Satisfaction & 0.21 \\
\cline { 3 - 4 } & & Solving Result Satisfaction & 0.52 \\
\hline & The possibility of a second choice & 0.30 \\
\hline & & The possibility of recommending to others & 0.30 \\
\cline { 3 - 4 } & & The possibility of long-term cooperation & 0.40 \\
\hline
\end{tabular}

\section{The fuzzy comprehensive evaluation procedure of customer satisfaction in logistics enterprises}

(1) The customer satisfaction of logistics enterprises is set as Level I index. Level II indicators include enterprise brand, service quality, customer loyalty, service price and customer complaint, which are expressed as A1, A2, A3, A4 and A5 respectively. The Level III index is the decomposition index of the level II index, which is expressed as $A i=\{A i j\}(i=1,2, \ldots 5 ; j=1,2, \ldots 4)$.

(2) The evaluation levels are set into 5, the comment set is $\mathrm{R}=\{\mathrm{R} 1, \mathrm{R} 2, \mathrm{R} 3, \mathrm{R} 4, \mathrm{R} 5\}, \mathrm{R} 1$ represent highly satisfied, R2 is satisfied, R3 is general, R4 is dissatisfied, R5 is highly dissatisfied.

(3) Synthetic fuzzy comprehensive evaluation result vector. The weight matrix A of customer satisfaction is combined with the membership degree matrix of customer satisfaction index (R), and the result vector B of fuzzy comprehensive evaluation is obtained.

\section{Empirical analysis - fuzzy comprehensive evaluation of customer satisfaction in Suzhou Yuancheng Express Company}

This article selects the Suzhou Yuancheng express to carry on the research on the customer satisfaction evaluation of the logistics enterprise, it mainly adopts the questionnaire survey method. A total of 160 questionnaires were issued to the customers of Yuancheng Express, 143 copies were collected, and the recovery rate of the questionnaire was $89 \%$. The validity and reliability of the questionnaire were tested by SPSS18.0. The results showed that the Cronbach's alpha values of all indicators were all greater than 0.75 , and the correlations between the indicators were all greater than 0.42 , which indicates that this questionnaire possess good reliability and validity. The customer satisfaction evaluation set is obtained by fuzzy statistical method, and the fuzzy comprehensive evaluation of the index weight of customer satisfaction evaluation is given in Table 1 . Thus, the membership matrix R of two level fuzzy evaluation and the result vector B of fuzzy comprehensive evaluation are formed.

$$
=\left(\begin{array}{lllll}
0.09, & 0.39, & 0.34, & 0.15, & 0.03
\end{array}\right) \quad\left[\begin{array}{ccccc}
0.09 & 0.42 & 0.34 & 0.13 & 0.02 \\
0.10 & 0.40 & 0.34 & 0.14 & 0.02 \\
0.07 & 0.39 & 0.32 & 0.16 & 0.06 \\
0.10 & 0.34 & 0.36 & 0.17 & 0.03 \\
0.09 & 0.32 & 0.35 & 0.20 & 0.04
\end{array}\right]
$$

After a series of calculations, it is concluded that the degree of highly satisfaction of Suzhou Yuan Cheng express company is 0.09 , the degree of satisfaction is 0.39 , the degree of general satisfaction is 0.34 , the degree of dissatisfaction is 0.15 , and the degree of highly dissatisfaction is 0.03 . It can be seen that the customers are generally satisfied with the logistics service of Suzhou Yuancheng express company. There are also differences in service standards based on different customers, so it also indicates that there are also some problems in the logistics service of the company. Through the evaluation of the 20 Level III indicators, it is found that customer satisfaction is low among the seven 
indicators, namely, the satisfaction degree of the solution process, the price comparison with the similar enterprises, the employee service attitude, the satisfaction of problem solving time, the freight tracking, the price performance ratio and the timeliness of dealing with the problems. Suzhou Yuancheng express company needs to constantly improve its lack of service, so that the customer satisfaction of the enterprise can be greatly improved.

\section{Improvement measures of customer satisfaction in logistics enterprises}

According to the statistical analysis results, there are three main reasons for customers' dissatisfaction with service quality, namely, service quality, service price and customer complaints. There are two main reasons for the dissatisfaction of the staff: slow complaint handling and poor service initiative. On the basis of the above analysis, the following improvement measures are put forward:

(1) Strengthening the management of logistics information

Although customers are only dissatisfied with the tracking of goods, the whole information system involves. Enterprise shall be customer information oriented and market oriented. The quality of Suzhou Yuancheng Express is good. When no order is received, a small amount of stock decision system is maintained according to the forecast. When the command requirement is received, it will start stocking and realize quick replenishment while reducing the cost. Customers can also track the transportation of their own goods through a perfect information system to facilitate their own delivery.

(2) Conduct differentiation management for targeted customer groups

In the premise of communicating with customers, the implementation of differentiated service to understand customer logistics requirements and establish different customer relationship according to the difference of importance, so as to provide products or services which are different from competitors, this is a different competition which is difficult to copy within a short period of time. For those customers who make a larger contribution, enterprise can provide them the VIP service, adopt the active service and even make the advanced service idea and service reserve. In terms of the service process, personnel, logistics equipment, etc,enterprises can meet the needs and provide special service for the customer, strive with the greatest efforts to meet the needs of customers. For instance, setting VIP Easy Access customer service hotline, equip special VIP customer service representative, provide one-to-one service for customers, thus enables the customers to feel the value-added services that the non VIP customers do not possess. For those relatively less important customers, enterprises can adopt standardized services from a cost saving point of view.

(3) Control of the logistics operation cost

In order to get customer satisfaction in terms of service price, Suzhou Yuancheng express must control its operation cost, such as transportation cost, warehousing cost, loading and unloading cost and management cost, etc. The control of these costs is not just a single cost control, as the cost of other aspects may increase while controlling an individual item, which may eventually lead to the increase of total cost. Therefore, the control of various costs should be carried out on the basis of mutual trade off. Under the condition that the operation cost is controlled, enterprises can adjust their service price appropriately, and they can apply price preference activities in the corresponding seasons or holidays, so that customers can get satisfactory service.

\section{Acknowledgement}

This research was financially supported by the MOE (Ministry of Education in China) Project of Humanities and Social Sciences(Project No.16YJC630078), Hubei Provincial Department of Education Project of Humanities and Social Sciences(Project No.16G151) and CFLP (China Federation of Logistics and Purchasing) Project(Project Number.2017CSLKT3-217). 


\section{References}

[1] Wu A H, Su J Q, Wang F. A Comprehensive Evaluation of the Logistics Service Quality Based on Vague Sets Theory, International Journal of Shipping and Transport Logistics, vol. 6, pp. 69-87, 2014.

[2] Musa A B, Comparative Study on Classification Performance between Support Vector Machine and Logistic Regression, International Journal of Machine Learning and Cybernetics, vol. 4, pp. 13-24, 2013.

[3] Huang B Q, Wang T, Xue X, Service-selecting Approach Based on Domain-specified QoS Model and its Application in Logistics, Service Industries Journal, vol. 32, pp. 1571-1588, 2012.

[4] Zhang G Q, Shang J, Li W L, An Information Granulation Entropy-based Model for Third-party Logistics Providers Evaluation,International Journal of Production Research, vol. 50, pp. 177-190, 2012.

[5] Hsiao H I, van der Vorst J, Kemp R, et al, Developing a Decision-making Framework for Levels of Logistics Outsourcing in Food Supply Chain Networks,International Journal of Physical Distribution \& Logistics Management, vol. 40, pp. 395-414, 2010. 